\title{
Promising Practices in Coaching Co-taught Preservice Clinical Experiences ${ }^{1}$
}

\author{
By Toni S. Strieker ${ }^{*}$,Woong Lim $^{\dagger}$, David Rosengrant ${ }^{*}$ \& \\ Marcia Wright ${ }^{+}$
}

In 2010, the National Council for Accreditation of Teacher Education (NCATE) called for colleges and universities to "turn teacher education upside down" (pg. 2) and focus on clinical experiences, rather than coursework. This charge resulted in major shifts in teacher education programs in the USA as colleges and universities forged new partnerships to create yearlong clinical experiences that included co-teaching and coaching. In 2018, the American Association of Colleges for Teacher Education (AACTE) Commission on Clinical Experiences recognized and described the mutual benefits of expanding these partnerships between schools and universities to include various forms of collaboration, coteaching and coaching. While these partnerships are increasing in number, little is known about the efficacy of the specific coaching approaches and practices employed in the co-taught classroom. This self-study examined the communication and behavioral approaches of 13 co-teaching coaches who collaborated with 39 teacher candidates enrolled in yearlong, co-taught P-12 clinical experiences. The co-teaching coaches attended up to four sessions of professional learning on co-teaching and coaching. Basic statistics were used to determine the demographics, the content of the coaching conversations, and preferred coaching approaches. The main data sources were the coaches' resumes, their reflections on goal-setting sessions, observation reports, and surveys on their daily coaching activities. Results indicated that effective coaches engaged in collaborative dialogue that moved candidates to selfdirected learning. Similarly, these results described the pedagogical practices of effective coaches in terms of goal-setting with the candidates, basic mentoring, and demonstration teaching.

Keywords: Teacher Education Reform, Clinical Experiences, Pre-service Coteaching, Student Teaching, Instructional Coaching

\footnotetext{
*Professor of Reading, Kennesaw State University, USA.

${ }^{\dagger}$ Assistant Professor of Mathematics Education, University of New Mexico, USA.

${ }^{\star}$ Associate Professor of STEM Education, University of South Florida - St. Petersburg, USA.

${ }^{+}$Part-time Assistant Professor, Kennesaw State University, USA.

${ }^{1}$ The first author and researcher presented the findings at the 20th Annual International Conference on Education of the Athens Institute for Education and Research in Athens, Greece on May 21, 2018. At the time of this conference, Drs. Toni Strieker and David Rosengrant are coaching 1st and 2nd year teachers whose induction is funded by the Woodrow Wilson Georgia Teaching Fellowship, a private foundation in Washington, D.C. committed to preparing high quality STEM teachers to work in America's high-poverty high schools
} 
In 2005, the Organization for Economic Co-operation and Development (OECD) commissioned a study on attracting, developing, and retaining teachers in 25 countries. According to these authors, in an effort to create a high social and economic order, countries around the world are seeking to improve their schools. Teachers, as the most expensive and significant resource in schools, are central to all school improvement initiatives. Furthermore, these authors report, "Improving the efficiency and equity of school depends in large measure on ensuring that competent people want to work as teachers, that their teaching is of high quality, and that all students have access to high quality teaching" (OECD, 2005, p. 1). More recently, Lewin (2011) reported that improvements in teacher effectiveness in the United States have resulted in changes to the accreditation standards (Council for the Accreditation of Educator Preparation [CAEP], 2015), particularly in terms of restructuring clinical experiences by means of schooluniversity partnerships.

In response to the international call, faculty members representing various teacher education programs formed interdisciplinary teams to design, develop, pilot and evaluate new approaches to clinical experiences (Strieker et al., 2017; Williams, Gray, \& Stockdale, 2012). These efforts resulted in a set of new approaches were aligned with the common variables of highly effective teacher education programs reported by Darling-Hammond (2006), including a common vision of teaching and learning, carefully crafted field experiences, theorization and justification of practice, focus upon the needs of the students, reflection on active pedagogy, engagement of collaborating teachers (CTs) as lifelong learners, and collaboration with their professional partners. In terms of positionality, the current study represents one investigation conducted as part of the larger research agenda of the interdisciplinary teams described above.

Over the past decade, numerous authors (Bacharach et al. 2010; Badiali \& Titus, 2010) have described effective co-teaching in pre-service teacher education. Yet, there is limited research on the characteristics and approaches of instructional coaches who forge a partnership with the collaborating teacher to support the teacher candidate during co-taught clinical experiences. Over the past ten years, researchers at our institution have explored various aspects of preservice coteaching, particularly in terms of the benefits of co-teaching (Heckert, Strieker, \& Shaheen, 2013), the content of the collaborative and reflective dialogue (Strieker, Adams, Lim, \& Wright, 2017), and the goals of the teacher candidates engaged in co-teaching coaching (Strieker, Shaheen, Hubbard, Digiovanni, \& Lim, 2014). The current study explores the communication and behavioral approaches of coteaching coaches situated in a collegial and reflective model of coaching, developed by, and for, teacher educators, along with their professional colleagues in P-12 schools. Furthermore, we examine the practices of 13 co-teaching coaches who are responsible for coaching 39 teacher candidates (assigned to 39 collaborating teachers) during a yearlong, co-taught P-12 teaching experience. Specifically, the following research questions guided our study: 
1. What are the characteristics of highly effective co-teaching coaches in terms of their years of experience, education, coaching approaches and practices?

2. What is the content of the dialogue between the coaches, the teacher candidates and the CTs as it relates to co-teaching?

3. What are the daily practices of highly effective coaches?

\section{Theoretical Framework, Conceptual Language \& Review of Literature}

The theoretical framework for this study draws heavily from activity theory (Saari \& Miettinen, 2001) and positioning theory (Harré \& van Langenhove, 1999). Both theories address how interpersonal communication and relationships reflect the roles assumed by individuals in social settings. According to activity theorists (Saari et al., 2001; Engestrom, 2000), all human activity is fundamentally goal-driven; is mediated by culture and language, rules and routines, materials and situation; and results in tangible outcomes. When applied to clinical experiences, the CTs and coaches assist candidates in achieving their goals by making decisions drawn from their own backgrounds of experience, knowledge, skill sets, as well as the situational demands and availability ofresources within the school. For example, the CTs assume responsibilities for mentoring the teacher candidatesand mediate their learning. Co-teaching coaches, on the other hand, facilitate the candidate's self-direction in his or her own professional learning. During the yearlong clinical experience, the coach and CT assume these influential roles and support the candidate's induction into the teaching profession.

To augment activity theory, we selected positioning theory (Harré et al., 1999), which describes position as a "...conceptual apparatus that allows for social constructionist theorizing based on a dynamic analysis of conversations and discourses" (p. 2). Thus, this theoretical approach provides a framework for understanding how individuals on a team define their roles and responsibilities in order to be effective educators (Bullough \& Draper, 2004).

Through this dynamic discourse, educators engage in high levels of cogenerative dialogue which requires them to use their knowledge and experience to analyze and describe their situation, to relate their personal stories, and ultimately, to solve the complex problems of practice that occur everyday in America's classrooms (Roth, 2004; Tobin \& Roth, 2010).

We begin to fully understand coaching and co-generative dialogue as an everdynamic and changing process (Roth \& Tobin, 2005) when we account for the history, culture and language of the school as well as the interpersonal interactions among the cooperating teacher, the teacher candidate and the co-teaching coach. According to Rogoff (1990), learning is not only personal; it is also interpersonal and situational. In 1993, Brandt, Farmer, and Buckmaster described a fluid process in which the mentor facilitates the learning process of a novice by scaffolding support, demonstrating and modeling procedures, and guiding the thought process. The novice, in turn, observes, approximates, reflects, and generalizes new knowledge and skills. In the world of P-12 education, not only do these mentors 
facilitate the professional practices of novice teachers, they also provide the vehicle for the acculturation of these new teachers to the school community.

\section{Literature Review}

Instructional coaching. Classroom coaching is a generic term for a number of practices that include Instructional Coaching (Knight, 2007), Differentiated Coaching (Kise, 2006, Literacy Coaching (Stover, Kissel, Haag, \& Shoniker, 2011), Content Coaching (Tschannen-Moran \& Tschannen, 2011) and Coteaching Coaching (Strieker, Shaheen, Hubbard, Digiovanni, \& Lim, 2014). In 2012, Knight and van Nieuwerburgh reported that instructional coaching positively impacted student achievement in P-12 schools.

According to Bearwald (2011) and Knight (2007), effective coaching is dependent upon interpersonal relationships and dialogue guided by the coach's ability to ask critical questions, rather than to simply offer solutions or make recommendations. In doing so, the coach facilitates a dialogue where teacher candidates and CTs have the opportunity to theorize the lesson and seek to understand the theory-to-practice (or practice-to-theory) implications as they cogenerate ideas for improving teaching and learning (Roth, Tobin, Camambo, \& Dalland, 2004). Thus, the interpersonal communication between the teacher candidate, the co-teaching coach and the CT drives the effectiveness of all concerned.

In our attempt to apply the principles and practices of coaching in P-12 schools to university preparation of P-12 teachers, we adopted Knight's (2007) Partnership Principles as the common language and conceptual framework for developing substantive interpersonal communication and substantive relationships to support collaboration, co-teaching, and co-generative dialogue. The Partnership Principles are: equality, choice, voice, dialogue, reflection, praxis, and reciprocity. Within the context of a co-taught clinical experience, equality implies that even though the candidates do not yet hold state teacher certification, their knowledge, skills, experience, and contributions hold equal value to those of the CT. Furthermore, each co-teacher has voice and choice in decision-making; therefore, the candidates' voices are heard throughout the cycle of co-teaching, including coreflection and co-generative dialogue (Strieker et al., 2014). After the candidate's monthly co-teaching observations, the co-teaching coach, CT, and teacher candidate form a triad and engage in co-generative dialogue to discuss their perceptions of the lesson observed and resolve complex problems of practice. The fluid nature of the approach supports the candidate in applying the knowledge and skills learned in university coursework to the realities of the classroom (praxis).

Interpersonal communication. The importance of the interpersonal communication and co-generative dialogue among members of the triad (e.g., coteaching coach, teacher candidate, and CT) cannot be underestimated. According to Hart (2018), communication among members of the triad form triatic and dyadic patterns at varying levels of frequency during the clinical experience. In addition to the frequency of patterns of communication among various groupings within the triad, the content of communication is also varied. The teacher 
candidates and their CTs often engaged in co-generative dialogue on complex problems of classroom management, differentiated instruction and assessment (Strieker, et al., 2014). Similarly, Valencia, Martin, Place \& Grossman (2009) found that candidates and their university discussed discipline-specific content, pedagogy and theory. In terms of influence on the development of teacher candidate efficacy, Lu (2007) described the CT as more influential than the university coach due to his or her daily interactions, observations and feedback to the candidate. In 2006, Baxter, Braithwaite, and Bryant described eight specific communication patterns among or between people who are engaged in triads on a regular basis in a traditional student teaching model. The communication patterns vary from the dysfunctional Closed Triad, which indicates no or ineffective communication, to the highly functional Open Triad, which indicates that communication is positive and flowing between and among all members of the group. Also, Baxter, et al. (2006) described functional dyads that dominate triads including the following: a) field-based triads dominated by CT and candidate; b) university-coalition triads dominated by university liaisons and candidate; and c) expert-coalition triads dominated by $\mathrm{CT}$ and university liaison. Finally, the researchers identified dyads positively linked to one member of the triad (CT, candidate or co-teaching coach) with another member. Finally, Elrod (2017) reported that open, reflective dialogue among all members of the triad positively impacted the professional and personal development of the candidate.

It is important to note that the literature is also replete with reports of interpersonal conflicts among members of the triads in traditional student teaching experiences. According to Rhoads, Samkoff, and Weber (2013), several types of tension commonly occur between the $\mathrm{CT}$ and the teacher candidate in traditional student teaching that often results from the CT's hesitation to shift power in the classroom to the candidate. This hesitation creates the CT's resistance to the candidate's selection of teaching methods and topics of content. Furthermore, hesitant CTs often challenge the candidate's capacity to manage their time, student behavior, and student learning. Finally, many CTs display the tendency to undermine their candidate by openly interrupting and/or disagreeing while the candidate is teaching.

Equally troubling are the reports of candidates being "stuck in the middle" between the university liaison and their $\mathrm{CT}$ in traditional student teaching. According to Bullough and Draper (2004), conflicting perceptions of candidate performance, mixed messages, and power struggles are also a source of conflict among members of the triad. All of these situations can and do result in ongoing difficulties in the interpersonal relationships between the candidate and the CT.

The literature from teacher education sources concerning interpersonal communication, dialogue, and co-teaching describes patterns and relationships that exist among the candidate, CT and university representative (Bullough et al., 2004; Rhodes, et al., 2013; Roth, et al., 2005; Strieker, Adams, Lim, \& Wright, 2017). Very few, if any, focus on these relationships when the triad is inclusive of an instructional coach. Furthermore, there are limited, if any, reports on the practices of instructional co-teaching coaches in clinical settings in teacher education. The fact that so few studies of this nature regarding coaching in teacher education are 
available underscores the need for the current study.

\section{Theoretical, Conceptual \& Operational Model of Pre-service Co-teaching and Coaching}

Figure 1. Cycle of Pre-service Co-teaching

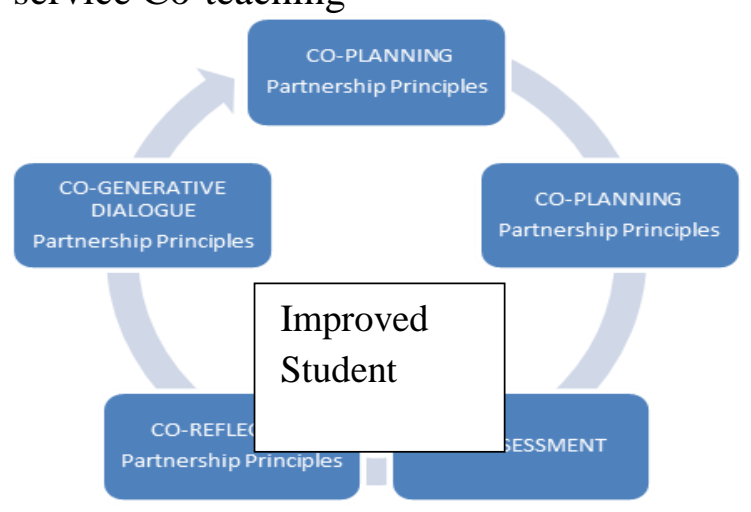

The theoretical, conceptual and operational model of pre-service co-teaching and coaching that was employed for the current study was originally reported by Strieker, et al., 2017. The model was designed and developed to mirror the cycle of teaching recommended by AACTE (2013) (see Figure 1). With an eye on improved student learning, the co-teachers engaged in an ongoing cycle of coplanning, co-instruction, co-assessment and co-reflection and co-generative dialogue. During the co-planning sessions, the co-teachers discussed curriculum standards, classroom management, classroom rules and routines, differentiated instruction, particularly in terms of how to use co-teaching to support equitable instruction. During co-instruction, the teacher candidate literally taught at the elbow (Roth \& Tobin, 2005) of the CT which provided ongoing opportunities for demonstration teaching. Also, during co-instruction, the co-teachers employed virtually all of the co-teaching structures offered by Cook and Friend (1995) and assisted students in making smooth transitions between large and small group activities. Finally, the co-teachers engaged in ongoing co-assessment and coreflection on student performance. To that end, the co-teachers were able to perform sophisticated classroom assessments including, benchmarking student behavior against classroom norms, conducting pre-assessments of prior knowledge, performance monitoring, formative and summative assessments.

The observations and feedback sessions conducted by the coaches focused on activities designated by the teacher candidate, the CT and the coach. The coteaching coaches had the flexibility to address any and all aspects of the coteaching cycle, including; but not restricted to, planning and implementation of research-based instructional strategies, co-teaching structures and approaches, formative and summative assessments, problem-solving approaches, etc. Coaches often facilitated the reflective dialogue that focused upon the candidate's plan for performance improvement. 


\section{Definitions and Terms}

Within the fields of instructional coaching and clinical experiences in teacher education, there is a multiplicity of terms that may cause confusion to the readers; therefore, we have provided definitions of terms that are pertinent to this investigation. Because the current research on clinical practice in teacher education was conducted as part of the multi-year, multi-phase research agendas of the first and second authors, several of the definitions were derived from previous research.

1. Pre-service Co-teaching was originally defined by Heck, Bacharach, Mann, and Ofstedal (2005) as "two teachers (a cooperating teacher and a teacher candidate) working together with groups of students; sharing the planning, organization, delivery and assessment of instruction, as well as, the physical space" (n.p.).

2. Co-teaching Coaching is a specialized form of instructional coaching where the coach guides the teacher candidate and the CT who co-teach one or more groups of students during the candidate's clinical experience. Coteaching coaching is a form of job-embedded professional development that relies upon virtual or real-time classroom observations and feedback. The goals of coaching are specific to the individuals and target improved performance for teacher candidate as well as their students. In some instances, the performance improvement goals may address improved collaboration and co-teaching with the CT.

3. The Communication and Behavioral Coaching Approaches used by the coaches in this study were derived from the previous work of Glickman, Gordan, and Ross-Gordan (2014). Glickman, et al., studied the communication of supervisors who adjusted their approaches based upon the developmental needs of their teachers. Glickman's 2014 rendition of supervisory roles ranged from expert to facilitative and the approaches ranged from Direct Control (DC) and/or Direct Informative (DI) to Collaborative (Col) and Non Directive (ND). While there is some overlap between the role and approaches used by our co-teaching coaches and developmental supervisors, our coaches maintained a no evaluative stance when working with the teacher candidates and CTs. Nonetheless, it was not uncommon for the candidates to request direct guidance from their coach and/or CT on implementation of specific strategies. Our coaches had the flexibility to demonstrate or explain specific teaching strategies, behavioral interventions, etc. On rare occasions when the coach was forced to take control of the situation, the candidate was immediately referred to the university supervisor for evaluation and feedback.

4. Co-generative Dialogue is a form of "structured discourse in which teachers and students engage in a collaborative effort to help identify and implement positive changes in a teacher's classroom teaching and learning practices" (Martin, 2006, p. 694).

4. Partnership Principles were originally developed by Knight (2007) who identified them as central to developing substantive interpersonal 
communication and substantive relationships to support collaboration, mentoring and other forms of collegial practice in education.

5. University Liaisons are university-based teacher educators (AACTE, 2018). For the purposes of this study, they are co-teaching coaches who may or may not also be employed as teacher education faculty.

\section{Method}

\section{Self-Study in Teacher Education Research}

The current investigation responded to Zeichner's (2007) call for self-study in teacher education by situating the present study in the larger context of research at our institution on the pedagogical practices of co-teaching coaches of practicing teacher candidates, enrolled in yearlong, co-taught clinical experiences. Our study was essentially a case study that used a dynamic action process case that allowed us to improve our program as the analysis unfolded. We followed this research tradition because it provided an effective tool for conducting systematic inquiry and program improvement.

\section{Program Context}

The co-teaching coaching programs and practices examined in this study were designed, developed, and analyzed at a state university, located in the metropolitan area of a large city in the southern region of the United States. The educator preparation program at this university graduates approximately 900 prospective teachers who complete initial certification programs in early childhood, elementary, middle and secondary education, special education, and instructional technology. Of those who graduated in 2015, approximately $82 \%$ self-reported as white (nonHispanic), $11 \%$ as black (non-Hispanic), $3 \%$ as Hispanic, $1 \%$ as Asian, $2 \%$ as multi-racial, and $2 \%$ undeclared. The teacher education unit is fully accredited by CAEP as well as by national professional associations.

\section{Informants in the Study}

All of the informants met the university guidelines for co-teaching coaches in that they had taught a minimum of four years and were certified in the content areas in which they coached, e.g., elementary, social studies, math, English, or physics. The cadre of co-teaching coaches was comprised of thirteen females and two males. Based upon their self-reports, four were retired school principals, twelve were retired teachers, and one was a member of the university faculty. All of the coaches had either engaged in co-teaching during their careers as teachers or as administrators who evaluated the co-teachers in their schools. Thirteen were Caucasian, one was Hispanic, and one was African American. While most of the coaches held a master's degree, one-third held doctoral degrees. The coaches reported a range of teaching experience from four to twenty-seven years, with an 
average of fifteen. The coaches reported less experience in actual university coaching. Twelve of the fifteen were in their first year of coaching. Of the three individuals who reported experience in university coaching, two people had two years and one person had three.

The co-teaching coaches were assigned to schools affiliated with one metropolitan school district that had a formal district-university agreement. According to the agreement, the district would host yearlong, co-taught clinical experiences in teacher education. To that end, during their senior year, teacher candidates were assigned to a qualified collaborating teacher, a university supervisor and a co-teaching coach. The co-teaching coaches who participated in this study were assigned to thirty-nine pairs of teacher candidates (along with their CTs) who were employed or interned in one of four elementary schools, two middle schools or three high schools in the same school district.

\section{Professional Learning Seminars for Teacher Candidates, CTs and Coaches}

The district agreed to assign our teacher candidates to CTs who would not only co-teach the entire year, but who would participate in professional development on how to use co-teaching, mentoring and instructional coaching. In order to build relationships and meaningful partnerships, the university agreed to send all of the co-teaching coaches who were assigned to the teacher candidates and CTs to the same seminars. The topics of professional learning included, but were not restricted to, the following: A Partnership Approach to Pre-service Coteaching; Foundations in Instructional Coaching; Coaching Classroom Management; Communication and Behavior Approaches to Coaching; Differentiated Coaching and Instruction. In addition, each co-teaching coach agreed to attend monthly sessions that specifically addressed research-based practices in coaching, facilitation, communication, and partnership development.

\section{Data Sources and Data Analysis Procedures}

The co-teaching coaches were responsible for submitting monthly reports, protocols, and reflections as well as brief surveys on their monthly activities. The data consisted of artifacts gleaned from the coaches' monthly reporting as well as attendance records from the seminars. Our coaches'monthly reporting typically included their completed observation reports, GROW protocol (adapted from Whitemore, 2002) and a monthly coaching co-teaching survey on a web-based data repository (see Appendix 1). Regular submission of this information provided a set of qualitative and quantitative data for our analysis.

Survey of effective practices of co-teaching coaches. To determine the practices of our co-teaching coaches, we developed a survey based upon the work of Knight (2008) that defined effective practices in mentoring, coaching and collaboration (see Appendix 1). The survey was designed to determine the frequencies that coaches engaged in research-based coaching practices, including: (a) candidate goal-setting; (b) instructional coaching on the "big four" instructional practices (e.g., co-teaching only, differentiated instruction, formative assessment, 
and classroom management); (c) coaching other instructional practices; (d) benchmarking student engagement; coaching on curriculum or content specific topics; (e) basic mentoring; (f) development of partnerships with CT; (g) demonstration teaching; (h) recommendations of resources; and/or (i) facilitation of co-planning. The surveys were developed by a multi-disciplinary team of faculty members who oversaw coaching in their program areas, e.g., elementary, middle or secondary programs (see Appendix 1).

Quantification of coaching practices and effectiveness. Our initial method to quantify our coaches' practices relied on the university data base for recruitment, professional development and accountability of our coaches. In an effort to evaluate the effectiveness of our coaches, particularly in terms of their collaboration with our candidates and CTs, we developed a simple mathematical formula. The formula derived from our study used a composite score (max. 14 points) totaled by adding 4 maximum points for co-teaching coaching approaches, 5 maximum points for content, and 5 maximum points for the indicators of contribution. To that end, co-teaching coaching approaches were defined as DC, DI, Coll and ND. The content of the content of the discussion among the coach, the collaborating teacher and the teacher candidate. The topics of conversation were categorized under five of the key elements of the co-teaching cycle, including the Partnership Principles (PP), Co-Planning (P), Co-Instruction (I), CoAssessment (A), and Co-Reflection (R) (see Figure 1. for descriptions of content of discussions.)

To determine coaching approach and content, the numbers indicate whether we found evidence (i.e., 1) or not (i.e., 0) of implementing an indicated method or content on the GROW protocol. The Collaboration \& Contribution score included 3 points and indicates how the contribution of teacher candidates and/or CTs was articulated on the GROW protocol- i.e., never noted ( 0 point), rarely noted (1 point), frequently noted ( 2 points), and always noted ( 3 points) respectively. Additionally, coaches received one point when there was unsolicited positive feedback from CTs or teacher candidates. A negative point was applied when the feedback was negative and a zero point was applied if there was no feedback.

The scores to represent the levels of educational degree were: Bachelor (1), Masters (2), and Doctorate (3). The Composite Score was derived from the total of Approach Score, Content Score, and the Collaboration \& Contribution Score. Table 1 illustrates the breakdown of composite scores for each co-teaching coach.

\section{Results}

\section{Quantitative Analysis}

The Pearson correlation coefficient was used to measure whether a positive or negative linear relationship occurred between the scores and the variables indicating experience, attendance, and education. We report that there was no statistically significant correlation between the scores and years of experience either teaching or administering programs, attendance at professional development, and/or determination of the highest year of degree obtained (see Table 1). 


\section{Calculation of Composite Scores and Ranking}

As noted above, formula derived from our study used a composite score (max. 14 points) totaled by adding 4 maximum points for co-teaching coaching approaches, 5 maximum points for content, and 5 maximum points for the indicators of contribution. Based upon these calculations, the composite scores of the co-teaching coaches were ranked from low $(+1)$ to high $(+11)$. The composite scores were then placed in three categories including, (a) Effective (8-11); (b) Emerging (6-7); and (c) Needs Development (5 and below). For our purposes, effective coaches were those who provided evidence of using facilitative methods and whose candidates emerged as self-directed learners. Coaches in need of development were those who provided evidence of maintaining their role of expert and whose candidates provided little evidence of self-directed learning. Table 2 describes the composite scores for each coach.

Table 1. Demographic Co-teaching Coaches

\begin{tabular}{|c|c|c|c|c|c|c|c|c|c|c|c|c|c|c|c|c|c|c|c|c|}
\hline \multirow[t]{3}{*}{ No } & \multirow{3}{*}{\begin{tabular}{|c|} 
Coacting \\
Placement
\end{tabular}} & \multicolumn{3}{|c|}{ Years of Experience } & \multicolumn{3}{|c|}{ Education } & \multicolumn{4}{|c|}{ Coaching Approaches } & \multicolumn{4}{|c|}{ Content of Cosching } & \multicolumn{3}{|c|}{$\begin{array}{l}\text { Indictators of } \\
\text { Contibutions }\end{array}$} & \multirow{3}{*}{$\left|\begin{array}{c}\text { Collaboration } \\
\& \\
\text { Contribution } \\
\text { Score }\end{array}\right|$} & \multirow{3}{*}{$\begin{array}{l}\text { Composite } \\
\text { Score }\end{array}$} \\
\hline & & & & & & & & & & & & Partnership & & co. & Co. & Co. & Teacher & Cooperating & & \\
\hline & & Cosching & Administration & Teaching & Degree & Cent Hit & Hirs of po & $D C$ & $\mathrm{Dl}$ & Collab & Non Direct & Principles & Co.plan $\mid$ & |nstrutet| & Assess & Reflett & Candidate & Teacher & & \\
\hline 1 & Elem & 3 & 27 & 13 & 2 & Elem & 4 & 0 & 1 & 0 & 1 & 1 & 1 & 1 & 0 & 1 & 1 & 1 & 3 & 11 \\
\hline 2 & Elem & 1 & 0 & 27 & 2 & Elem & 2 & 0 & 0 & 1 & 1 & 1 & 1 & 1 & 1 & 1 & 0 & 0 & 3 & 10 \\
\hline 3 & Elem & 2 & 15 & 15 & 2 & Elem & 3 & 0 & 1 & 1 & 1 & 1 & 0 & 1 & 0 & 1 & 1 & 0 & 3 & 10 \\
\hline 4 & Middle & 1 & 0 & 8 & 1 & Middle & 2 & 0 & 0 & 1 & 1 & 1 & 1 & 1 & 1 & 1 & 0 & 0 & 1 & 8 \\
\hline 5 & Secondary & 1 & 0 & 4 & 3 & Secondary & 1 & 0 & 0 & 0 & 1 & 1 & 1 & 1 & 1 & 1 & 1 & 0 & 1 & 8 \\
\hline 6 & Secondary & 1 & 5 & 1 & 3 & Secondary & 1 & 0 & 0 & 0 & 1 & 1 & 1 & 1 & 0 & 1 & 0 & 1 & 1 & 1 \\
\hline 1 & Elem & 1 & 10 & 20 & 1 & Elem & 2 & 0 & 1 & 0 & 0 & 0 & 1 & 1 & 0 & 0 & 1 & 1 & 2 & 1 \\
\hline 8 & Elem & 1 & 0 & 37 & 2 & Elem & 2 & 0 & 1 & 0 & 1 & 1 & 1 & 1 & 0 & 0 & 0 & 0 & 1 & 6 \\
\hline 9 & Secondary & 1 & 0 & 25 & 1 & Secondary & 2 & 1 & 1 & 0 & 0 & 1 & 1 & 1 & 0 & 1 & 4 & .1 & 2 & 6 \\
\hline 10 & Elem & 1 & 0 & 30 & 1 & Elem & 2 & 0 & 1 & 1 & 0 & 0 & 1 & 1 & 0 & 1 & 4 & 0 & 2 & 6 \\
\hline 11 & Secondary & 1 & 0 & 6 & 1 & Secondary & 1 & 0 & 0 & 0 & 1 & 1 & 1 & 1 & 1 & 0 & 0 & 0 & 1 & 6 \\
\hline 12 & Elem & 1 & 8 & 8 & 3 & Elem & 2 & 0 & 0 & 1 & 0 & 1 & 1 & 1 & 1 & 1 & 1 & .1 & 1 & 5 \\
\hline 13 & Midolle & 2 & 0 & 20 & 2 & Middle & 4 & 1 & 1 & 0 & 0 & 0 & 1 & 1 & 0 & 0 & 0 & 0 & 1 & 5 \\
\hline 14 & Midole & 1 & 10 & 6 & 2 & Middle & 2 & 0 & 0 & 1 & 0 & 1 & 0 & 1 & 0 & 0 & 0 & 0 & 1 & 4 \\
\hline 15 & Secondary & 1 & 4 & 1 & 1 & Secondary & 2 & 0 & 0 & 0 & 0 & 0 & 0 & 1 & 0 & 0 & 0 & 0 & 0 & 1 \\
\hline
\end{tabular}

One option to test the reliability of our formula as a performance metric was to compare the results with those of an internal evaluation measure. If the two measures drew similar conclusions, the reliability was established. Thus, once the composite scores were derived, the co-teaching coaches' composite scores were rank-ordered from high to low. The scores and ranking were then shared with the coordinators of the coaching program who compared these results their own with internal evaluation of the coaches. Based upon those comparisons, the coordinators verified the ranking. 


\section{Discussion}

\section{Characteristics of Effective Co-teaching Coaches}

Based upon these results, there were five coaches whose scores attained the rank of Effective (see Table 1). Among them, three coached in elementary schools, one in middle school social studies classrooms, and one in high school mathematics classrooms. The effective coaches distinguished themselves with strong indicators of collaboration, including facilitation of dialogue with contributions of the teacher candidates and the CTs. Further, the effective coaches provided evidence of using Coll and ND coaching approaches. For example, one high school coach noted, "As a team, we all agreed on the same coaching goal to give Sarah (the candidate) increased opportunities for feedback on her instructional decisions and efforts."

Furthermore, all five coaches who were designated as effective reported that they had intentionally facilitated dialogue used Partnership Principles (e.g. voice, choice, etc.) to assist the $\mathrm{CT}$ and teacher candidates to define and develop positive and productive working relationships. For example, the high school math coach reported, "Sarah and CT appear to have a good working rapport. They claim to have similar teaching philosophies and beliefs." Similarly, all five coaches described their facilitation of co-generative dialogue where the candidates revealed the self-directed nature of their learning. For example, the middle school coach stated,

"During our reflective dialogue, the candidate expressed that he felt his (coaching) goals were met for this particular lesson as he continues to do well with all of his classes. He is still struggling a bit with 2 nd period in terms of getting all of the students to perform. He is working closely with the CT to continue to try different strategies to motivate some of his students."

Similarly, an elementary coach described the growth of her candidate and the power of her relationships as,

"She [the candidate] seems confident in her abilities because of the great experiences that she has had this year. She is anxious about graduation, moving, finding a job and starting her 'real life,' but does not seem anxious about her teaching ability. Her CT has provided her with a wealth of resources and experiences and I'm certain that [the candidate] will feel free to contact her for advice as she begins her first teaching job."

\section{Analysis of Activities of Effective Co-teaching Coaches}

The monthly surveys of the effective co-teaching coaches were analyzed to determine the research-based practices that they employed on a regular basis. All of the effective coaches facilitated the candidate's goal-setting during the initial conferences with the candidate and CT, which ultimately resulted in goals that were supported by all three individuals. This is distinctively different from the 
coaches who were ranked as Need Development who did not facilitate goal-setting meetings. Rather, the coaches in the Need Development group worked exclusively with the candidate and minimized the role of the CT.

Three of the five effective coaches used the GROW framework (Whitemore, 2002) to support their candidates in establishing personal improvement goals, developing plans to meet their goals,monitoring their progress, and establishing the roles of the CT and coach (see Appendix 2). The other two effective coaches used a structured interview approach. Virtually all of them facilitated conversations where the triad (e.g., CT, candidate and coach) discussed the current reality in the classroom and school, goals for improved candidate performance, and procedures to monitor the candidate's progress in meeting his or her goals, often on improving student learning. Depending on the level, all effective coaches, regardless of their personal tendencies to assume expert or facilitator roles, facilitated goal-writing sessions. Consequently, all candidates established personal improvement goals aimed at high quality teaching of complex content, including structured programs to support emergent literacy, advanced mathematical formulas, and critical thinking about reporting on historical events. To that end, only the high school math coach, who had recently graduated with her Ph.D. in Math Education, used demonstration teaching to model research-based practices in instructing tenthgraders on quadratic formulas.

Two elementary effective coaches and the middle school effective coach were asked by the candidate and CT to benchmark student engagement in their classrooms during whole class instruction. To that end, the coaches used the procedures identified by Sprick, Knight, Reinke, Skyles, and Barnes (2010) to benchmark, describe, and establish goals and monitor improvements on behaviors related toteacher-student interactions, student-to-student interactions, disruptions, engagement, and student responses to instruction. The middle school coach described the success of the procedures with a candidate assigned to a "high energy" 6th grade class:

"Data collected during the observation of this lesson included two spot checks for engagement using the Academic Engagement monitoring form. During our reflective dialogue, I asked the candidate what percentage of students she thought were actively engaged during my check. Her response was [a figure] lower than what I recorded. During the lesson the Time on Task was 100\% at one point and $98 \%$ at the end! Although the class was loud in terms of the volume, the students were on task and learning was taking place."

The two elementary coaches reported similar responses to their benchmarking procedures. One CT found it so effective that she shared the practices with her colleagues who did not host a teacher candidate. They, in turn, requested the coach to benchmark the behaviors of the students in their classrooms!

Finally, all five effective coaches described situations in which they conducted basic mentoring of candidates in terms of program requirements for graduation, professional networking, tips for job interviews, and other career-supporting strategies. 


\section{Practices of Effective Co-teaching Coaches}

It was interesting to note that virtually all of the effective co-teaching coaches describe co-reflection, and ultimately, co-generative dialogue with all of their teacher candidates and CTs. (This was not the case with coaches who scored in the Directive group.) Specifically, our high school coach stated, "During co-planning and co-reflection, Sarah (teacher candidate) and her CT discuss[ed] typical student misconceptions and ways to support their learning...Later during co-instruction, the CT walked around the room helping students, while Sarah taught the lesson." Similarly, one elementary coach reported one session that reflected the candidate's, CT's and coach's co-assessment and co-reflection on the observation data. She observed, "We discussed ways to keep the students involved... Flexibility is essential and he is seeing this."

\section{Implications and Vision for the Future}

\section{Vision for the Future}

In 2018, the AACTE Clinical Practice Commission provided guidance to teacher education programs throughout the USA. In this report, the commission provided The Mutual Benefit Proclamation (p. 38-39) which described the advantages of "properly credentialed professionals who have a mutual respect and appreciation for each other's roles and responsibilities in preparing future educators." AACTE went on to describe the need for mentoring of teacher candidates by CTs and university liaisons (e.g., faculty and/or co-teaching coaches) in non-evaluative ways that focus on coaching, co-teaching, dialogue and reflection. Our vision for the future includes ways to systematically operationalize the recommendations of these national and international organizations, particularly in terms of defining effective coaching practices. In the future, we envision coaching in clinical experiences in preservice education and beyond. To that end, we recommend further investigation of the efficacy of coaching teacher candidates in alternative certification paths and MAT programs, very much like what the Woodrow Wilson Georgia Teacher Fellowship Program has initiated in the USA.

\section{Recommendations for Future Practices}

While still in the beginning stages, we feel that the approaches described in this paper and presentation hold promise for future teacher educators and teacher candidates. Our effective coaches demonstrated the capacity to support the development of teacher candidates in implementing research-based, high leverage practices. The goal-setting and monitoring processes (particularly GROW) seemed to provide a vehicle for the candidate, CT, and coach to explore and expand their relationships and to encourage reflective, co-generative dialogue. These practices also provide prospective coaches with various frameworks and data collection procedures which, when used in combination, also offer specific measures for 
candidates to use to monitor their own progress as well as the progress of their P12 students. Thus, based upon these findings, we recommend that university coaches and CTs receive ongoing professional learning on implementing effective communication, facilitation, and pedagogical practices to ensure that coaching be more facilitative, relational, and reflective.

Implementation of GROW beyond pre-service education. As a result of the successful utilization of the GROW document with our pre-service teachers, we have been able to implement it with a select group of our graduates. In 2014, the university described above was awarded funding for a Woodrow Wilson Georgia Teacher Fellowship Program for STEM education. In addition to completely revamping the Masters of Arts in Teaching preparation program, we needed to critically examine our support for our graduates during their induction into teaching.

When individuals enter the fellowship program, each person commits to a three-year induction program with the university. This program is focused on a triad with the fellow, a school-based mentor, and a university mentor. The schoolbased mentor is typically someone who has had multiple years of experience in the school and is close in discipline to the fellow. The university mentor typically is someone at or associated with the university. The $3^{\text {rd }}$ author of this paper serves as the university mentor for physics candidates even though he is no longer at the institution. He has a background in physics education which is analogous to the other university faculty who have extensive backgrounds in their content area. He has taught classes or has completed research with the fellows, thus forging a personal connection, which is critical.

This triad meets twice in the fall semester and twice in the spring semester. The first meeting consists of a discussion to identify the main goals for the firstyear teaching fellow based upon individual strengths and weaknesses, teaching assignments (i.e. AP Physics versus Physical Science), school culture and future goals of the fellow. The fellow then completes a GROW document and gathers evidence for working towards or achieving the goal (typically a video of classroom instruction). These are all uploaded to a secured online repository so that at the second meeting of the semester, everyone in the triad has a chance to view and discuss the work. The first meeting of the spring session thus far has typically resulted in a modification of the GROW document from the previous semester. The teaching fellow then uploads more evidence of working towards the goals in her/his GROW document. In the second meeting during the spring semester, the data is reviewed while discussing the plan for the following year.

We saw major changes in the fellow's goals after the first year, compared to those generated for the second semester in the same year. These modifications were usually attributed to a difference in the types of classes taught, in some cases to a change in school assignments, or to an increase in the fellow's view of where he/she needed to improve. These areas were selected based upon internal reflections or scores on observations from supervisors.

The induction work is generally met with positive reviews from the fellows. They recognize that the extra reflections are beneficial to their growth as a teacher, though the time commitments (especially in the first year) are challenging. The 
fellows greatly value the resources and expertise that their mentors offer them. For example, one of the fellows is discussing with the author ways to implement virtual reality (a research area of the third author) into his physics classroom or to possibly work together on a future project.

\section{Limitations of Study}

First, university faculty had limited input as to where teacher candidates should be placed, and with whom, while in the field. As a result, the placement in the study could have been random- some teacher candidates were fortunate to work with CTs who actively engaged in collaboration and co-teaching, while others were not. Some teacher candidates engaged in the entire cycle of coplanning, co-instruction, co-assessment, and co-reflection while others were not. This particular limitation, when looking at this work through the lens of self-study, is a factor that is not likely to change and reflects the reality of many teacher education programs in the USA. Our program necessarily faces the disconnect between the faculty, researchers, co-teaching coaches, candidates and the collaborative teachers from various educational settings. One clear outcome of such a disconnect is the inconsistent (or sometimes) broken clinical experiences of our teacher candidates. We believe co-taught clinical experiences have the potential to create the opportunity to increase the communication and collaboration among faculty, researchers, coaches, candidates and teachers.

The second limitation of the study was the participant sample. First of all, the sample was one of convenience. All of the teachers who participated in the study worked in a single district that had negotiated a school-university agreement to host, co-teach, and work with a co-teaching coach during the teacher candidates' yearlong clinical placements. Second, the sample size was which limited the generalizability of the results of the study. This study did not intend to generalize results but to reflect on our findings relative to the operative nature (see the variables of our metric) of co-taught clinical experiences. Future studies that use multiple study sites, with larger sample sizes, could reduce potential bias associated with the findings of this study.

\section{Acknowledgements}

Funds to support this research were received from two partnership teacher education grants, including the following:

- The Woodrow Wilson Georgia Teaching Fellowship program (20142018), a partnership between Kennesaw State University and the Woodrow Wilson Fellowship Foundation, Princeton, New Jersey, USA.

- Kennesaw State University \& the Cobb County School District Teacher Quality Partnership Grant, US Department of Education (2009-2015), Grant Award Number U3365090070. 


\section{References}

American Association of Colleges for Teacher Education (AACTE) (2018). A pivot toward clinical practice, its lexicon, and the renewal of educator preparation. Report of the AACTE Clinical Practice Commission. Retrieved from www.aacte.org/cpcfull-report-final/.

American Association of Colleges for Teacher Education (2013). edTPA. Retrieved from http://edtpa.aacte.org

Bacharach, N., Heck, T., \& Dahlberg, K. (2010). Changing the face of student teaching through co-teaching. Action in Teacher Education, 32(1), 3-14.

Badiali, B., \& Titus, N. (2010). Co-teaching: Enhancing student learning through mentorintern partnerships. School-University Partnerships, 4(2), 74-80.

Baxter, L. A., Braithwaite, D. O., \& Bryant, L. E. (2006). Types of communication triads perceived by young-adult stepchildren in established stepfamilies. Communication Studies, 57(4), 381-400. doi: 10.1080/10510970600945923

Bearwald, R. (2011). It's about the questions. Educational Leadership, 69(2), 74-77.

Brandt, B. L., Farmer, J. A., \&Buckmaster, A. (1993). Cognitive apprenticeship approach to helping adults learn. New Directions for Adult and Continuing Education, 1993(59), 69-78.

Bullough, R.V., \& Draper, R. J. (2004). Making sense of a failed triad: Mentors, university supervisors and positioning theory. Journal of Teacher Education, 55(5), 407-420.

Cook, L., \& Friend, M. (1995). Guidelines for creating effective practices. Focus on Exceptional Children, 28, 1-5.

Council for the Accreditation of Educator Preparation (CAEP). (2016). Retrieved from http://www.caepnet.org

Darling-Hammond, L. (2006). Constructing $21^{\mathrm{st}}$ century teacher education. Journal of Teacher Education, 57(3), 300-314.

Elrod, M.J. (2017). Exploring mathematics teacher education fieldwork experiences through storytelling. Retrieved from ProQuest Digital Dissertations.

Engestrom, Y. (2000). Activity theory as a framework for analyzing and redesigning work. Ergonomics, 43(7), 960-974.

Glickman, C.D., Gordan, S.P., \& Ross-Gordan, J. M. (2014). SuperVision and instructional leadership: A developmental approach (9ed.). Saddle Creek, NJ: Pearson.s-p.]

Heck, T., Bacharach, N., Mann, B., \& Ofstedal, K. (2005). Extreme makeover: Student teaching edition. Paper presented at the annual meeting of the Association of Teacher Educators, Chicago.

Heckert, J., Strieker, T., \& Shaheen, M. (2013). Kennesaw State University: Collaborative clinical practice. Educational Renaissance, 1(2), pp. 83-96.

Harré, R. \& van Langenhove, L. (1999). The dynamics of social episodes. In R. Harré and L. van Langenhove (Eds.), Positioning theory. Oxford: Blackwell Publishers.

Hart, A. (2018). Exploring the interpersonal dynamics of the supervisory triad of preservice teacher education: A qualitative meta-synthesis. (Doctoral dissertation). Retrieved from https://bit.ly/2NLDvMb.

Kise, J. (2006). Differentiated coaching: A framework for helping teachers change. Thousand Oaks, CA: Corwin.

Knight, J. (2007). Instructional coaching: A partnership approach to improving instruction. Thousand Oaks, CA: Corwin Press, Inc.

Knight, J. (Ed.) (2008). Mentoring, collaboration and coaching. Laureate Education, Inc. Thousand Oaks, CA: Corwin Press, Inc.

Knight, J., \& van Nieuwerburgh, C. (2012). Instructional coaching: A focus on practice. 
Coaching: An International Journal of Theory, Research and Practice, 5(2), 100-

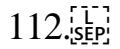

Lewin, T. (2011, July 21). Training of teachers is flawed, study says. New York Times. Retrieved from http://www.nytimes.com/2011/07/21/education/21teaching.html

Lu, H.L. (2007). Mentor teachers, program supervisors, and peer coaching in the student teaching experience: A phenomenological study of the experiences of mentor teachers, program supervisors, and interns.(Doctoral dissertation). Retrieved from ProQuest Digital Dissertations.

Martin, S. (2006). Where practice and theory intersect in the science classroom: using cogenerative dialogue to identify the critical point in science education. Cultural Studies of Science Education, 1(4), pp. 690-720.

National Council for Accreditation of Teacher Education. (2010). Transforming teacher education through clinical practice: A national strategy to prepare effective teachers. Report to the blue ribbon panel on clinical preparation and partnerships for improved student learning. Retrieved from www.ncate.org/publications

Organisation for Economic Co-operation and Development (2005). Teachers matter: Attracting, developing and retaining effective teachers. Retrieved from http://www. oecd.org/edu/school/48627229.pdf.

Rhoads, K., Samkoff, A., \& Weber, K. (2013). Student teacher and cooperating teacher tensions in a high school mathematics teacher internship: The case of Luis and Sheri. Mathematics Teacher Education \& Development, 15(1), 108-128.

Rogoff, B. (1990). Apprenticeship in thinking: Cognitive development in social context. New York: Oxford University Press, 1990.

Roth, W.-M. (2004). Activity theory and education: An introduction. Mind, Culture, and Activity, 11(1), 1-8.

Roth, W.-M., Tobin, M., Camambo, C., \& Dalland, C. (2004). Co-teaching: Creating resources for learning and learning to teach chemistry in urban high schools. Journal of Research in Science Teaching, 41(9), 882-904. doi:10.1002/tea.20030.

Roth, W.-M., \& Tobin, K. (Eds.) (2005). Teaching together, learning together. New York, NY: Peter Lang.

Saari, E., \& Miettinen, R. (2001). Dynamics of change in research work: Constructing a new research area in a research group. Science, Technology \& Human Values, 26(3), 300-321.

Stover, K., Kissel, B., Haag, K., \& Shoniker, R. (2011). Differentiated coaching: Fostering reflection with teachers. The Reading Teacher, 64(7), 509-530.

Sprick, R., Knight, J., Reinke, W., Skyles, T., Barnes, L. (2010). Coaching classroom management: Strategies and tools for administrators and coaches. Eugene, OR: Pacific Northwest Publishing, Inc.

Strieker, T., Adams, M., Lim, W., \& Wright, M. (July, 2017). Using discourse to understand the relationships and practices of pre-service co-teachers. Georgia Educational Researcher, 14(1). doi:10.20429/ger2017.140102.

Strieker, T., Lim, W., Hubbard, D., Crovitz, D., Gray, K., Holbein, M., \& Steffen, C. (2017). The pursuit of a collegial model of clinical practice: The story of one university. Action in Teacher Education, 39(2), 118-137, doi:10.1080/01626620.20 16.1245637.

Strieker, T., Shaheen, M., Hubbard, D., Digiovanni, L., \& Lim, W. (Winter, 2014). Transforming clinical practice through coaching pre-service co-teaching. Educational Renaissance, 1(2), 39-62.

Tobin, K., \& Roth, W.-M. (2010). Implementing coteaching and cogenerative dialoguing in urban science education. School Science and Mathematics, 105(6), 313-322.

Tschannen-Moran, B., \& Tschannen-Moran, M. (2011). The coach and the evaluator. 
Educational Leadership, 69, 10-16.

Valencia, S.W., Martin, S.D., Place, N.A., \& Grossman, P. (2009). Complex interactions in student teaching: Lost opportunities for learning. Journal of Teacher Education, 60(3), 304-322. doi: 10.1177/0022487109336543.

Whitemore, J. (2002). Coaching for performance: Growing people, performance and purpose $\left(3^{\text {rd }}\right.$ ed.). London: Nicholas Brealey.

Williams, D., Gray, K., \& Stockdale, S. (2012). Ready, set, go: It's middle school. Current Issues in Middle Level Education, 17(2), 16-20.

Zeichner, K. (Jan, 2007). Accumulating knowledge across self-studies in teacher education. Journal of Teacher Education. doi: 10.1177/0022487106296219. 


\section{Appendix 1}

Monthly Co-Teaching Coaches' Survey

Coach Name/Content Area/Level:

Month: Jan February March April

Directions: Identify your teams by name and check the coaching activities conducted this month.

\begin{tabular}{|c|c|c|c|c|}
\hline Coach Activities & Team 1 & Team 2 & Team 3 & Team 4 \\
\hline \multirow{3}{*}{$\begin{array}{cl}\text { Development of Goal } \\
\text { - } & \text { Teacher Candidate } \\
\text { - } & \text { Co-teaching Team } \\
\text { - } & \text { Student Impact }\end{array}$} & $\mathrm{TC}$ & TC & $\mathrm{TC}$ & TC \\
\hline & Co-T & Co-T & Co-T & Co-T \\
\hline & SI & SI & SI & SI \\
\hline \multirow{4}{*}{$\begin{array}{ll}\text { Advisement on Big Four } \\
\text { - Co-teaching Only } \\
\text { - Differentiated } \\
\text { - Instruction } \\
\text { - } \text { Formative Assessment } \\
\text { Classroom } \\
\text { Management }\end{array}$} & Co-T & Co-T & $\mathrm{Co}-\mathrm{T}$ & Co-T \\
\hline & DI & DI & DI & DI \\
\hline & FA & FA & FA & FA \\
\hline & $\mathrm{CM}$ & $\mathrm{CM}$ & $\mathrm{CM}$ & $\mathrm{CM}$ \\
\hline \multirow{4}{*}{$\begin{array}{l}\text { Benchmark Behavior/Student } \\
\text { Engagement } \\
\text { - Interactions } \\
\text { - Disruptions } \\
\text { - Engagement } \\
\text { - Student Response }\end{array}$} & Interact & Interact & Interact & Interact \\
\hline & Disrupt & Disrupt & Disrupt & Disrupt \\
\hline & Engage & Engage & Engage & Engage \\
\hline & $\begin{array}{l}\text { SRespons } \\
\text { e }\end{array}$ & $\begin{array}{l}\text { SRespons } \\
\mathrm{e}\end{array}$ & $\begin{array}{l}\text { SRespons } \\
\mathrm{e}\end{array}$ & $\begin{array}{c}\text { SRespons } \\
\mathrm{e}\end{array}$ \\
\hline \multirow{3}{*}{$\begin{array}{l}\text { Advisement on Instructional } \\
\text { Practices } \\
\text { - Cooperative Learning } \\
\text { - Inquiry-based Learning } \\
\text { - Other }\end{array}$} & $\mathrm{CL}$ & $\mathrm{CL}$ & $\mathrm{CL}$ & $\mathrm{CL}$ \\
\hline & I-B L & I-B L & I-B L & I-B L \\
\hline & Other & Other & Other & Other \\
\hline \multirow{2}{*}{$\begin{array}{l}\text { Advisement on Content-related } \\
\text { Issues } \\
\text { - GPS/CC } \\
\text { - Other }\end{array}$} & GPS/CC & GPS/CC & GPS/CC & GPS/CC \\
\hline & Other: & Other: & Other: & Other: \\
\hline \multicolumn{5}{|l|}{$\begin{array}{l}\text { Examination of } \text { Student } \\
\text { Achievement Data }\end{array}$} \\
\hline \multicolumn{5}{|l|}{$\begin{array}{l}\text { Recommendation of } \\
\text { Resources }\end{array}$} \\
\hline \multicolumn{5}{|l|}{ Facilitation of Co-planning } \\
\hline \multicolumn{5}{|l|}{ Demonstration Teaching } \\
\hline \multicolumn{5}{|l|}{ Basic Mentoring } \\
\hline \multicolumn{5}{|l|}{ Partnership Development } \\
\hline Other: & & & & \\
\hline
\end{tabular}




\section{Appendix 2}

\section{Adapted GROW: A Goal-setting Framework*}

Goal: The candidate establishes an overarching goal for the final semester of the yearlong clinical that addresses planning, assessment, instruction, impact on student learning, or other. Use the "other" category when the candidate has idiosyncratic concerns that are not necessarily instructional, e.g. relationship issues.

Reality: The supervisor facilitates a discussion of the PLC to determine if the goal is realistic in the current context (or reality). Sample Questions: Do the students have pre-requisite knowledge? What experiences or courses have you had that have prepared you to conduct this task? Next the PLC determines the process for measuring, recording, observing or collecting evidence of mastery. Sample Questions: What types of data should we collect that will be the most useful to you? Who will collect the data?

Opportunities and alternatives. The PLC creates a plan of how to develop, refine or revise current practices to reach the goal as well as the alternative approaches, strategies, etc. Discuss theoretical considerations relative to the various approaches as well as the research underlying the practice. Sample DS Questions: What are some strategies or activities you could employ to achieve your desired outcome? Are there specific student who need something extra or different? How can you use co-teaching to help meet those needs? What are the theories that underpin your stated opportunities and alternatives? Whodoes what, when and why? The PLC completes a brief plan of action to determine the roles and responsibilities of the supervisor, the CT, and the candidate. Sample Questions: What do the teacher candidate and collaborating teacher see as an appropriate role for the supervisor? What models of co-teaching do the teachers feel would best support their instruction and students? When (and how) can they co-plan? Specifically, what will the teacher candidate do? Specifically, what will the collaborating teacher do in terms of co-assessment, co-instruction, co-problem-solving.

Candidate's Growth Statement: The candidate provides a statement of their understanding of how implementing this plan will result in their professional growth, as well as the growth of their students. There is an expectation that the candidate will be able to make general references to underlying theories and/or research. Sample Questions: What motivated you to create this as a goal? What do you hope to learn from this? What impact will this have upon the learners in your class?

*Adapted from Whitemore (2002) by T. Strieker, K. Dooley, \& M.K. Widener. 
